\title{
PENGAJUAN ANALISA MARKETING MIX-4P TERHADAP PURCHASE INTENTION PRODUK AQUA DI DKI JAKARTA
}

\author{
Airin Anggraeni Sutedjo \\ Program Studi Magister Manajemen Universitas Tarumanagara \\ airin.anggraeni.s@gmail.com
}

\begin{abstract}
This research aims to analyze the effect Marketing Mix-4P on consumer's Purchase Intention towards Aqua Product in DKI Jakarta. Data used in this research were obtained from questionnaires (primary). Sampling Methods used in this study using the NonProbability Sampling Method, in which each element in the population does not have the opportunity or the same opportunity to be selected as a sample. The technique used is Convenience Judgment Sampling because the respondents selected are respondents who are willing and can help answer the research questions asked. To facilitate the study, the researcher has determined the criteria to be used in the sample selection in this research. The sample used by the researcher is people who live in DKI Jakarta province.

Research findings show that the four Marketing Mix variables used in this study, Price, Product, and Promotion variables have a significant effect on Aqua Product Purchase Intention. Meanwhile, the Marketing Mix variable that does not provide significant impact to Aqua Product Purchase Intention is Place. The contribution of the four Marketing Mix variables included in the analysis model of the Purchase Intention of Aqua Products is $47.3 \%$ and the rest of $52.7 \%$ is influenced by other factors not tested in this study.
\end{abstract}

Keywords: Marketing Mix, Product, Price, Promotion, Place, Consumer's Purchase Intention

\section{Pendahuluan}

Air merupakan kebutuhan dasar yang bersifat primer karena kebutuhan air minum yang layak dan aman dikonsumsi semakin hari semakin meningkat jumlahnya. Bisnis Air Minum Dalam Kemasan (AMDK) semakin menggiurkan, karena kebutuhan akan air minum terus meningkat seiring dengan pertumbuhan penduduk. Agar dapat menguasai pangsa pasar yang lebih besar dan maksimal, perusahaan produksi air minum dalam kemasan saat ini menggunakan kapabilitas yang semaksimal mungkin di pasar domestik dan asing. Disini peran bauran pemasaran (Marketing Mix) menjadi kunci dalam meningkatkan sales dan market share suatu perusahaan. Salah satunya adalah PT Tirta Investama (Danone Group), sebuah perusahaan Fast-Moving Consumer Goods (FMCG) dengan produk air minum dalam kemasannya, Aqua, yang dipublikasikan di Indonesia pada tahun 1973. Dikarenakan marketing mix merupakan salah satu dari faktor utama dalam merancang strategi marketing dalam meningkatkan sales, dalam penelitian ini penulis menggunakan faktor dalam marketing mix seperti: kualitas produk, kesesuaian harga, intensitas promosi dan akses distribusi dari produk Aqua untuk memberikan insight kepada pihak manajemen PT Tirta Investama guna meningkatkan penjualannya. Sehubungan dengan hal tersebut, maka penulis memilih judul "Analisa Marketing Mix-4P Terhadap Purchase Intention Produk Aqua di DKI Jakarta”.

\section{Hipotesis}

$\mathrm{H} 1$ = Terdapat pengaruh product terhadap purchase intention

$\mathrm{H} 2$ = Terdapat pengaruh price terhadap purchase intention

$\mathrm{H} 3$ = Terdapat pengaruh promotion terhadap purchase intention 
$\mathrm{H} 4$ = Terdapat pengaruh place terhadap purchase intention

$\mathrm{H} 5$ = Terdapat pengaruh simultan dari variabel product, price, promotion, dan place terhadap purchase intention

\section{Tinjauan Pustaka}

Marketing Mix atau bauran pemasaran dapat disebut "seperangkat alat intervensi di pasar" (Gilanina sebagaimana dikutip dari Horovitz, 2003).

Gambar 1. Konsep Marketing Mix

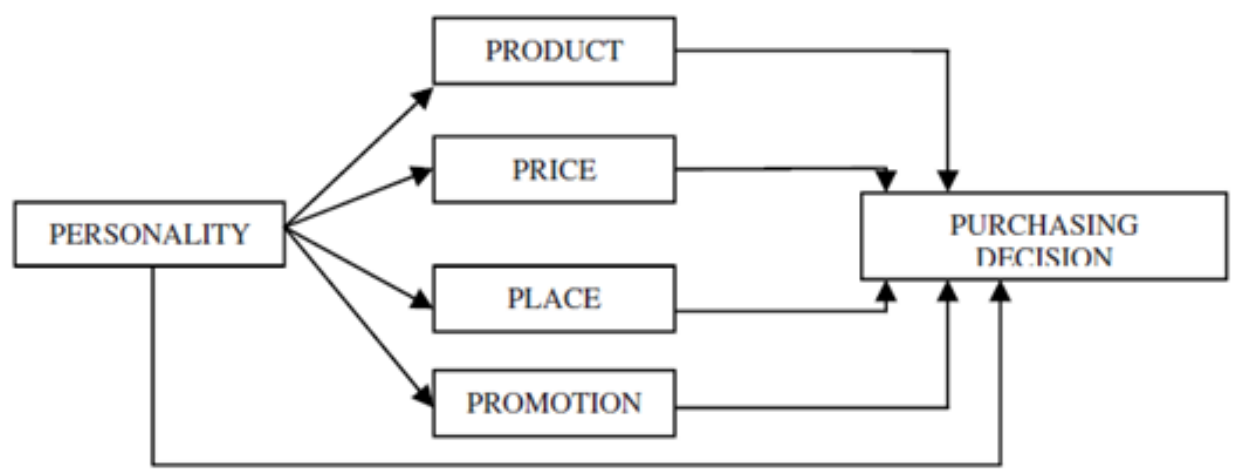

Berdasarkan Gambar 1 di atas, Marketing Mix terdiri atas empat buah elemen utama dalam mendukung aktivitas Marketing, antara lain: Product, Price, Place, dan Promotion. Product merupakan objek (nyata) atau jasa (tidak nyata) yang diproduksi atau dihasilkan dan ditawarkan kepada pelanggan di pasar (Gordon, sebagaimana dikutip dari McCarthy, 1960). Product adalah segalanya untuk perhatian, perolehan, penggunaan atau konsumsi yang dapat dipasarkan dan dapat memuaskan kebutuhan atau keinginan. Product adalah barang yang lebih nyata. Product termasuk objek fisik, layanan orang, tempat, organisasi, ide produsen atau kombinasi dari ini (Gilanina, sebagaimana dikutip dari Kotler \& Armestrang, 2000).

Price merupakan sarana marketing yang digunakan untuk memposisikan dan membedakan suatu produk dengan produk yang lainnya (Abril, sebagaimana dikutip dari Yoo et al, 2000). Price dapat didefinisikan sebagai sejumlah yang dibayar pelanggan terhadap produk atau jasa, yang pada umumnya berupa economic cost (Gordon, sebagaimana dikutip dari McCarthy, 1960). Place adalah tempat di mana pelanggan menerima produk dan jasa, serta mencakup proses perpindahan produk atau jasa dari produsen ke konsumen akhir "(pp. 1057). Place merupakan strategi keseluruhan mengenai distribusi, di mana terdapat dua macam strategi, pertama organisasi langsung ke konsumen dan strategi kedua adalah melalui distributor yang menyediakan produk atau jasa kepada pelanggan (Gilanina, $\mathrm{tt}$ ).

Promotion merupakan aktivitas pengembangan yang dilakukan perusahaan untuk menyediakan informasi baik mengenai value dari produk kepada pembeli dan untuk mendorong pelanggan membeli produk atau jasa (Mehrabi et al., 2014). Promotion merupakan alat komunikasi yang dapat menyampaikan pesan ke audiens yang dituju. Pada dasarnya, promotion bertujuan untuk menginformasikan, membujuk dan mempengaruhi (Gilanina, sebagaimana dikutip dari Roosta \& et al, 2007, p247).

Konsep Purchase Intention dikemukakan oleh Chia Lin- Hsu (sebagaimana dikutip dari Yoo et al., 2000), yang menyatakan bahwa purchase intention adalah kecenderungan konsumen untuk membeli sebuah produk. Hal ini sangat penting untuk mengenali purchase intention pelanggan karena kebiasaan pelanggan (consumer's behavior) dapat diprediksikan dengan niatnya atau intention-nya (Park and Kim, 2016). Wu et al. (2015) juga mendefiniskan purchase intention sebagai sebuah sarana penghubung bagi pelanggan untuk membeli produk dan kemungkinannya untuk membeli. Purchase intention dilihat sebagai 
variabel hasil atau outcome penting dalam penelitian ini, dan termasuk di dalamnya sebagai dependent variable atau variabel tidak bebas.

\section{Metode Riset}

Penelitian ini mengumpulkan data dengan menyebarkan kuesioner yang dibagikan secara acak (random) kepada konsumen produk Aqua di wilayah Jakarta sebanyak 100 lembar. Kuesioner akan dibagi menjadi dua bagian. Bagian pertama berisi pertanyaan screening dan informasi tentang responden (jenis kelamin, usia, tempat tinggal, dll) yang dibuat untuk memastikan responden masuk ke dalam kualifikasi. Bagian kedua berisi pertanyaan mengenai Marketing Mix 4-P (Product, Price, Place, dan Promotion), di mana penelitian ini menggunakan skala Likert untuk mengetahui tanggapan dari responden terhadap indikator dari variabel yang ditanyakan.

Analisa regresi digunakan dalam penelitian ini untuk memprediksikan hubungan antara variabel Y terhadap variabel X nya (Zahid sebagaimana dikutip dari Lund, 2012). Metode analisa yang digunakan dalam penelitian ini adalah metode analisa linear berganda. Menurut Hair et al. (2010), regresi linear berganda adalah model regresi dengan dua atau lebih variabel independen. Regresi linear berganda digunakan untuk menguji pengaruh dua atua lebih variabel independen terhadap variabel dependen dan melihat hubungan antara variabel independen dan variabel dependen. Persamaan regresi linear berganda dalam penelitian ini adalah sebagai berikut: Purchase Intention $=b o+b 1$ Product + b2Price + b3 Place + b4Promotion + error

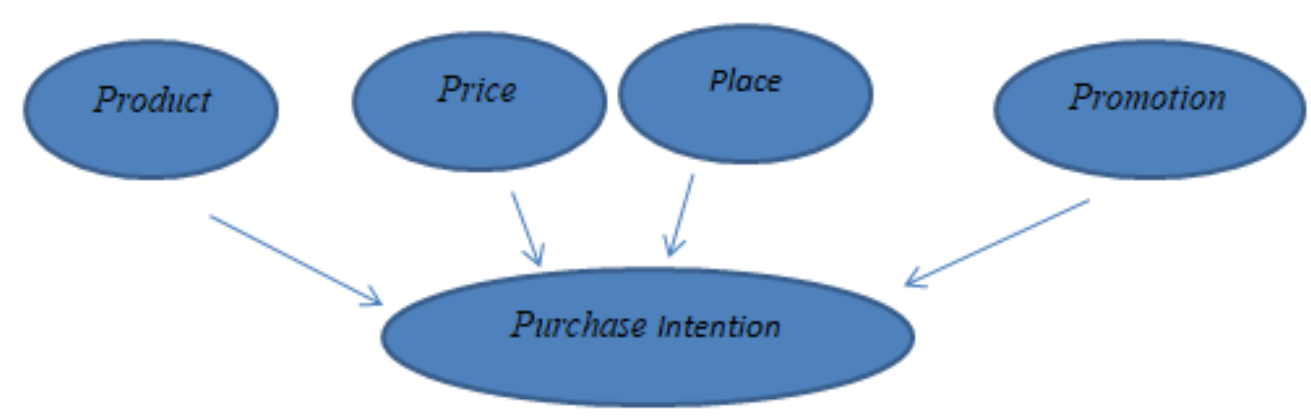

Gambar 2. Kerangka Berpikir Penelitian

Berdasarkan Gambar 2, Variabel dalam penelitian ini adalah variabel yang paling mempengaruhi pertimbangan pelanggan untuk memotivasi pelanggan memilih produk Aqua dan tanggapan atas produk Aqua yang sudah beredar saat ini.

Variabel yang digunakan dalam penelitian ini adalah:

1) Variabel Operasional yang merupakan variabel bebas (Independent Variable) yang disimbolkan dengan X. Variabel bebas daam penelitian ini antara lain Product, Price, Place, dan Promotion

2) Variabel Purchase Intention yang merupakan variabel terikat (dependent variable) yang disimbolkan dengan $\mathrm{Y}$.

\section{Hasil}

Penelitian ini mengumpulkan data dengan menyebarkan kuesioner yang dibagikan ssecara acak (random) kepada konsumen produk Aqua di wilayah DKI Jakarta sebanyak 100 lembar. Kuesioner akan dibagi menjadi dua bagian. Bagian pertama berisi pertanyaan screening dan informasi tentang responden (jenis kelamin, usia, tempat tinggal, dll) yang dibuat untuk memastikan responden masuk ke dalam kualifikasi. Bagian kedua berisi pertanyaan mengenai Marketing Mix 4-P (Product, Price, Place, dan Promotion), di mana 
penelitian ini menggunakan skala Likert untuk mengetahui tanggapan dari responden terhadap indikator dari variabel yang ditanyakan. Seluruh kuesioner yang dikembalikan telah diisi dengan lengkap oleh responden kemudian peneliti memasukkan jawaban yang terdapat pada 100 buah kuesioner tersebut dan mengolahnya dengan SPSS.

\section{A. Uji Validitas dan Reliabilitas}

Pengujian validitas menggunakan program SPSS dengan dasar pengambilan keputusan uji validitas menurut Widyasari (sebagaimana dikutip dari Santoso, 2000) sebagai berikut:

- Jika r-hitung > r-tabel, maka item pertanyaan dinyatakan valid

- Jika r-hitung < r-tabel, maka item pertanyaan dinyatakan tidak valid

Nilai r-tabel dapat dilihat pada tabel $r$, dengan $\mathrm{n}=100$, $\mathrm{df}=\mathrm{n}-2=98$, serta nilai signifikansi $=0,05$, didapatkan nilai r-tabel $=0,197$. Dalam penelitian ini, didapatkan bahwa seluruh nilai r-hitung lebih besar dari r-tabel $(0,197)$, maka dapat disimpulkan bahwa item - item dalam kuesioner yang disebarkan valid.

Menurut Haddad (sebagaimana dikutip dari Sekkaran, 2000), menyatakan bahwa uji reabilitas dilakukan dengan menghitung Croanbach's alpha untuk setiap faktornya dan titik kritis yang direkomendasikan bernilai 0,6. Dalam penelitian ini, didapatkan bahwa nilai Croanbach's alpha untuk seluruh variabel bernilai di atas 0,6, sehingga dapat disimpulkan bahwa kuesioner yang disebarkan bersifat reliabel.

\section{B. Deskriptif Karakteristik Responden}

Dalam penelitian ini, diketahui bahwa sebagian besar responden berjenis kelamin wanita dengan presentase $71 \%$ atau sebanyak 71 orang orang responden. Sementara sisanya $29 \%$ atau sebanyak 29 orang orang responden berjenis kelamin pria. Diketahui bahwa pada umumnya responden berusia 21 - 25 tahun sebanyak 68 orang responden dengan presentase sebesar 68\%, sisanya berusia dibawah 21 tahun sebanyak 2 orang responden dengan presentase sebesar $2 \%$, berusia $26-30$ tahun sebanyak 21 orang responden dengan presentase sebesar $21 \%$, berusia 31 - 35 tahun sebanyak 6 orang responden dengan presentase sebesar $6 \%$, berusia $36-40$ tahun sebanyak 1 orang responden dengan presentase sebesar $1 \%$, dan berusia $41-45$ tahun sebanyak 2 orang responden dengan presentase sebesar $2 \%$. Berdasarkan domisili, diketahui bahwa sebagian besar responden berdomisili di Jakarta Barat sebanyak 68 orang responden dengan presentase sebesar $68 \%$, berdomisili di Jakarta Pusat sebanyak 12 orang responden dengan presentase sebesar $12 \%$, berdomisili di Jakarta Selatan sebanyak 10 orang responden dengan presentase sebesar 10\%, berdomisili di Jakarta Timur sebanyak 1 orang responden dengan presentase sebesar $1 \%$, dan berdomisili di Jakarta Utara sebanyak 9 orang responden dengan presentase sebesar $9 \%$.

\section{Hasil Analisis Data \\ Uji Normalitas}

Uji normalitas dilakukan untuk mengetahui apakah di dalam model regresi variabel dependen dan variabel independen keduanya memiliki distribusi normal atau tidak. Salah satu cara termudah untuk melihat normalitas residual adalah dengan melihat grafik Normal P-P Plot of Regression Standarized Residual yang membandingkan antara data observasi dengan distribusi mendekati distribusi normal. 


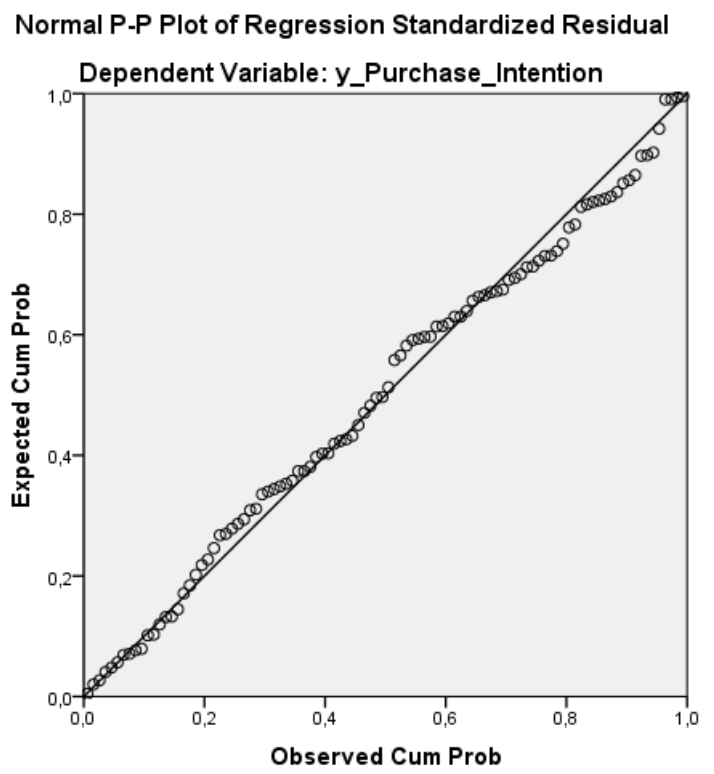

Gambar 3. Uji Normalitas (Grafik Normal P-P Plot of Regression Standarized)

Berdasarkan Gambar 3 di atas, terlihat bahwa titik - titik menyebar di sekitar garis diagonal dan mengikuti garis diagonal, berarti model regresi normal dan layak dipakai untuk memprediksi variabel bebas.

Uji Multikolinearitas dapat dilihat dari nilai Tolerance dan nilai VIF. Jika nilai Tolerance bernilai lebih dari 0,100 dan VIF bernilai kurang dari 10,00, maka dapat disimpulkan bahwa pada model regresi tidak terdapat masalah multikolinearitas. Dalam penelitian ini, didapatkan bahwa nilai Tolerance bernilai lebih dari 0,100 dan VIF bernilai kurang dari 10,00, sehingga dapat disimpulkan bahwa pada model regresi tidak terjadi masalah multikolinearitas.

Uji heteroskedastisitas memiliki tujuan untuk menguji apakah dalam model regresi terjadi ketidaksamaan variance dari residual satu pengamatan ke pengamatan yang lain. Heteroskedastisitas terjadi jika variance dari residual satu pengamatan ke pengamatan lain tidak tetap, sementara itu homoskedastisitas terjadi jika variance dari residual satu pengamatan ke pengamatan lain tetap. Model regresi yang baik adalah yang terjadi homoskedastisitas, bukan heteroskedastisitas. Hasil Uji Heteroskedastisitas disajikan pada Gambar 4 berikut ini.

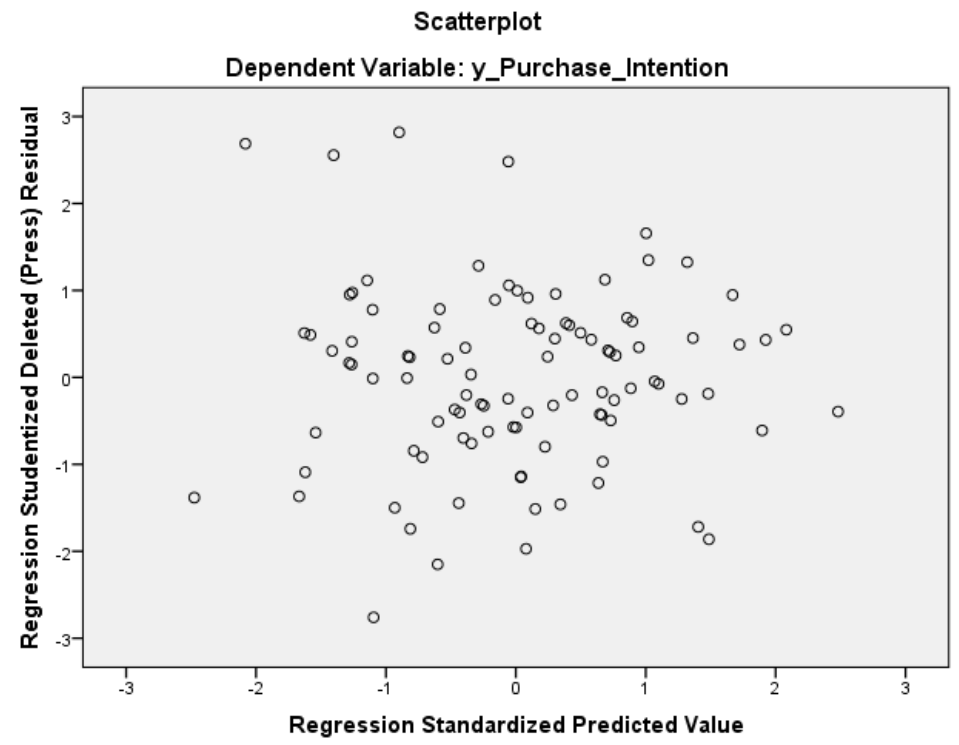


Gambar 4. Hasil Uji Heteroskedastisitas

Berdasarkan Gambar 4, terlihat bahwa titik - titik menyebar dengan membentuk pola yang tidak jelas, sehingga dapat disimpulkan bahwa pada model regresi tidak terjadi masalah Heteroskedastisitas (Hair, 2010).

\section{Analisis Regresi Ganda}

Hasil pengolahan regresi ganda menggunakan SPSS adalah sebagai berikut:

\section{Tabel 1. Hasil Uji t}

\begin{tabular}{|rl|r|r|r|}
\hline Model & & $\mathrm{B}$ & $\mathrm{t}$ & Sig. \\
\hline \multirow{2}{*}{} & (Constant) & 10,324 & 2,996 & $0,003^{* * *}$ \\
& & 0,546 & 4,205 & $0,000^{* * *}$ \\
& x1_product & 0,525 & 3,118 & $0,002^{* * *}$ \\
1 & x2_Price & 0,323 & 1,984 & $0,05^{* *}$ \\
& x3_Place & 0,299 & 2,863 & $0,005^{* * *}$ \\
\hline
\end{tabular}

***. signifikansi pada $\alpha 0,01$

**. signifikansi pada $\alpha 0,05$

*. signifikansi pada $\alpha 0,10$

Berdasarkan Tabel 1 di atas, seluruh nilai signifikansi variabel memiliki nilai di bawah $0,05(<0,05)$ kecuali untuk variabel Place, di mana variabel Place memiliki nilai signifikansi 0,05. Hal ini menunjukkan bahwa variabel Product, Price, dan Promotion berpengaruh positif terhadap Purchase Intention Produk Aqua.

\section{Kesimpulan}

1. Dari keempat variabel Marketing Mix yang digunakan dalam penelitian ini, variabel Price, Product, dan Promotion memberikan pengaruh yang signifikan terhadap Purchase Intention Produk Aqua. Sementara itu, variabel Marketing Mix yang tidak memberikan pengaruuh secara signifikan terhadap Purchase Intention Produk Aqua adalah Place

2. Kontribusi keempat buah variabel Marketing Mix yang dimasukkan ke dalam model analisis terhadap Purchase Intention Produk Aqua ini adalah sebesar 47,3\% dan sisanya sebesarr $52,7 \%$ dipengaruhi oleh faktor - faktor lainnya yang tidak diujikan dalam penelitian ini

\section{DAFTAR PUSTAKA}

Abril, C., \& Rodriguez-cánovas, B. (2016). European Journal of Management Marketing mix effects on private labels brand equity. European Journal of Management and Business Economics, 25(3), 168-175.

Bahman, S. P., Kamran, N., \& Mostafa, E. (2013). The effect of marketing mix in attracting customers: Case study of Saderat Bank in Kermanshah Province. African Journal of Business Management, 7(34), 3272-3280. 
Gilaninia, S., Taleghani, M., \& Azizi, N. (tt). Marketing Mix And Consumer Behavior. Kuwait Chapter of Arabian Journal of Business and Management Review, 2(12), 53-58.

Gordon, R. (2012). Rethinking the social marketing mix, Australasian Marketing Journal, $1(2), 2-5$.

Haddad, M., Judeh, M., \& Haddad, S. (2011). Factors Affecting Buying Behavior of an Apartment an Empirical Investigation in. Research Journal of Applied Sciences, Engineering and Technology, 3(3), 234-239.

Hashim, N., \& Hamzah, M. I. (2014). 7P's: A Literature Review of Islamic Marketing and Contemporary Marketing Mix. Procedia - Social and Behavioral Sciences, 130, 155159.

Hsu, C. L., Chen, M. C., Kikuchi, K., \& Machida, I. (2017). Elucidating the determinants of purchase intention toward social shopping sites: A comparative study of Taiwan and Japan. Telematics and Informatics, 34(4), 326-338.

Karbala, A., \& Wandebori, H. (2012). Analyzing the Factors That Affecting Consumer' s Purchase Intention in Toimoi Store, Indonesia. 2nd International Conference on Business And Economics, Management and Behavioral Sciences, 80-83.

Mehrabi, J., Nasiri, L., \& Mansuri,M. (2014). Investigating and Priotity of (4P) Factors On Costumer Decision For Marketing Strategy,2(5), 592-595.

Nargesi, S., Jamali, S., \& Babaei, S. (2013). Comparative Study of Traditional and Online Marketing Mix Willingness To Purchase the Cultural Products. Kuwait Chapter of Arabian Journal of Business and Management Review, 2(11), 33-48.

Widyasari, S., \& Fifilia, E. T. (2009). ANALISIS PENGARUH PRODUK, HARGA, PROMOSI DAN LOKASI TERHADAP KEPUTUSAN PEMBELIAN RUMAH ( Studi pada Perumahan Graha Estetika Semarang ). Telaah Manajemen, 6(2), 159-169.

Yeu, C. S., Leong, K. C., Tong, L. C., Hang, S., Tang, Y., Bashawir, A., \& Subhan, M. (2012). A Comparative Study on International Marketing Mix in China and India: The Case of McDonald's. Procedia - Social and Behavioral Sciences, 65(ICIBSoS), 10541059.

Zahid, W., \& Dastane, O. (2016). Factors Affecting Purchase Intention of South East Asian ( SEA ) Young Adults towards Global Smartphone Brands. Asean Marketing Journal, $8(1), 66-84$. 


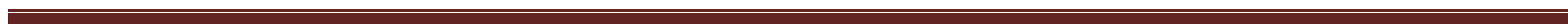
$\cdot$ 